\title{
Determining the effect of storage conditions on the natural drying of radiata pine logs for energy use
}

\author{
Rien Visser ${ }^{1 *}$, Hamish Berkett ${ }^{2}$ and Raffaele Spinelli ${ }^{3}$
}

\begin{abstract}
Background: The effect of storage duration and technique on the moisture content of radiata pine (Pinus radiata D. Don) biomass logs in New Zealand was studied.

Methods: Two trials were established in the South Island to represent favourable and unfavourable storage conditions, namely: summer storage in a warm and dry location and winter storage in a cold and relatively wet location. In total twenty stacks were installed, each consisting of approximately $600 \mathrm{~kg}$ of radiata pine logs (wet initial weight), with treatments intended to compare small diameter logs, large diameter logs, large diameter logs split, as well as the effect of cover. Moisture content was gravimetrically determined at the beginning and the end of the trials. All stacks were weighed at 1 to 4 week intervals to follow the weight loss trend over time.
\end{abstract}

Results: After 24 weeks in summer storage, the moisture content (wet basis) of radiata pine logs decreased from an initial value of 53\% to between 33 and 21\%. The decrease was greatest for uncovered small logs and decreased was smallest for covered large logs. Due to wet and cold weather conditions, logs stored in winter- dried very little over a 17-week period. Moisture content decreased from an initial value of 58\% to between 51 and 49\%, with no significant treatment differences observed in the winter trial.

Conclusions: The best summer storage technique was the simplest and consisted of stacking small logs without any cover. The larger logs dried the slowest, but splitting accelerated drying significantly. Covering did not help and results indicated that, while covering is useful for preventing rewetting of dry logs, it does not improve drying of wet logs.

Keywords: Biomass, Quality, Moisture content, New Zealand

\section{Background}

National energy policies increasingly support the use of forest biomass for energy supply due to its contribution to climate change mitigation, community welfare and local development (Stupak et al. 2007). That is especially true for the European Union but also for many other countries, including New Zealand (Pennial 2008; Hall and Jack 2009). Hence, the growing demand for wood fuels must be matched by an expanding supply in order to guarantee price stability (Hillring 1997). This is crucial to the development of a viable biomass energy sector, where fuel represents a major cost item (Junginger et al. 2006). For the same reason, use efficiency must be maximised, by best allocation and quality upgrading.

\footnotetext{
* Correspondence: rien.visser@canterbury.ac.nz

${ }^{1}$ Director of Studies Forest Engineering - Canterbury University, Private Bag, 4800 Christchurch, New Zealand

Full list of author information is available at the end of the article
}

Different sources will generate fuel types with different quality characteristics, affecting the choice and the performance of the conversion technology (Chau et al. 2009). The most important physical characteristic of wood fuels is moisture content, which determines heating value, storage properties and transport costs (Petterson and Nordfjell 2007; Hall 2000, EECA 2010) and is generally integrated in the fuel pricing structure (Spinelli et al. 2010). Moisture content (on a wet mass basis) of green biomass often exceeds 50\%, which is too high for small-scale energy conversion facilities (Strelher 2000). High moisture content generally causes operational problems in the boilers, with process instability and higher emissions (Svoboda et al. 2009). It also lowers the gasification temperature, increasing the production of tars and decreasing both gas quality and conversion efficiency (Brammer and Bridgwater 1999).

Drying of raw biomass prior to combustion or gasification can increase power production efficiency between 3 
and 5\%, depending on the drying method and the initial moisture content of the biomass (Mcllveen-Wright et al., 2001; Spets \& Ahtila, 2002). That may justify heating raw wood fuels in order to obtain rapid active drying (Johansson et al. 1997). Active drying is also the most effective way to bring moisture content below fibre saturation point, which typically occurs at a moisture content around 20-25\% (Walker 2006). However, conventional active drying may incur significant energy and financial cost (Ragavhan et al. 2005), and may lead to the release of harmful volatile compounds (Rupar and Sanati 2003). Hence the recurring interest for more effective techniques, such as multi-stage drying (Holmberg and Ahtila 2004), solar convection (Reuss et al. 1997) and mechanical drying (Yoshida et al. 2010). All try to make a less intense use of external inputs, to save on energy and cost.

The least intense use of external inputs comes with natural drying, which relies exclusively on the moisture gradient between wood and ambient air. This is the traditional drying system applied to firewood, and it is very effective if handling and storage conditions are properly managed. After trees are felled, the rate of natural drying depends on many factors, including ambient temperature, relative humidity, wind speed, precipitation, tree species and tree size (Petterson and Nordfjell 2007). Drying rate can be predicted with appropriate models, which can return reasonably accurate estimates (Hart 1982). However, these models often apply to sawn lumber rather than logs (Simpson and Hart 2001) and generally require a good knowledge of the diffusion coefficient of the species concerned, which restricts their general application (Simpson and Wang 2003).

Despite the specific character and the significant biomass potential of radiata pine (Pinus radiata D. Don) logging residues (Hall and Jack 2009), few of these studies have concerned radiata pine. Hall (2000) described the rate of drying as well as the effect of storage on piled and comminuted logging residues. Exposed stem residue and branches dried quickly, but comminuted material dried little over the seven-month test period. A study by the New Zealand Clean Energy Centre (2009) used bins to collect logging residues and dried them through three seasons. The residues were placed in a pile on bearers to encourage airflow, and treatments included unprocessed and processed, indoor and outdoor, as well as uncovered and covered. An important result was that summer drying could reduce moisture to $25 \%$ (wet basis) and that the subsequent delivered cost of the dried residue at $\$ 3 / G J$, which includes the cost of drying, is lower than the delivered cost of raw material at \$3.20/GJ.

Integration of residue recovery into an actual logging operation can reduce residue cost as well as provide for a less contaminated product (Baker et al. 2010). However, by increasing the complexity and landing space requirements for a harvesting crew, the overall cost of harvesting will be greater. One concept to overcome this issue, as well as to benefit from infield drying prior to transportation of the residue, is to stack residues either at the side of the operational landing, or transport it to a nearby recently completed landing (Visser et al. 2009). This effort would only be justified if significant drying took place to offset the handling cost. Opportunities to split large wood, or cover the log stacks, to facilitate drying would also need to be justified through improved drying potential.

While it would be best to define a general law for predicting the effect of storage conditions on natural drying, it seems more practical to address each local situation with specific studies, which is the policy followed by most researchers (Suadicani and Heding 1992). Therefore, the goals of this study were to determine the natural drying rate of radiata pine logs, as a function of storage conditions and technique. In particular, the study explored the effect of: 1) storage duration, 2) storage season, 3) log size, 4) log splitting and 5) cover.

\section{Methods}

The experiment consisted of two trials, one conducted in summer and the other in winter to help understand the drying effects at 'favourable' and 'unfavourable' sites. The 'favourable' summer trial was established in Mosgiel (Otago) at a quarry, and is typically dry with a warm wind. The 'unfavourable' winter trial was located on a farm near Okuku (Canterbury), where winter is characterised by low temperature and relatively high humidity. Both sites were located on flat open ground, exposed to sun and wind, as generally appropriate when building wood stores.

On each site, logs were stacked on purpose-built pallets, each representing an experimental unit. Pallets were chosen for the study as they can be weighed at intervals to ascertain moisture loss and avoid the need for destructive sampling of the logs. In commercial operations logs would never be dried on pallets, although they would normally be stacked in a manner that maximized airflow. It would be reasonable to surmise that the logs on these relatively small pallets would be exposed to more airflow and solar energy, but also more rainfall, on a per unit volume basis. They could also be expected to dry more uniformly as compared to a large stack. A limitation of this study is that results cannot be transferred directly to a commercial scale log drying operation.

Pallets were produced by a local manufacturer and fitted with wooden uprights to safely retain the logs. All pallets were placed on cinder blocks to prevent contact with the ground and to allow easy lifting and weighing. Each pallet contained about $600 \mathrm{~kg}$ of logs (fresh initial weight), cut to an average length of $1.8 \mathrm{~m}$. Logs were 
largely debarked, due to repeated handling during harvesting, processing and recovery. They were separated into two size classes based on their diameter - "small" $(<35 \mathrm{~cm})$ and "large" $(\geq 35 \mathrm{~cm})$. Half of the large logs were split prior to bucking, using an excavator with a ripping tine. Logs were stacked on the pallets to a height of approximately $1.6 \mathrm{~m}$. Plastic tarpaulin was used for the "covered" pallets, whereby it covered the top and approximately halfway down the sides of the stack, but did not cover the log ends.

Twenty stacks were established, 12 in summer at the Mosgiel site and 8 in winter at the Okuku site (Table 1). Overall, the trial consisted of 13 fresh tonnes (initial weight) of radiata pine logs. The factorial design of stack replicates was incomplete, due to funding constraints. However, multiple samples were collected from each stack at the end of the tests, and these were used as replicates for the estimate of final moisture content, allowing a conclusive evaluation of factor effects. The summer trial was established in November 2009 and dismantled in May 2010, thus lasting 24 weeks. The winter trial was established in May 2010 and dismantled in September of the same year, thus lasting 17 weeks.

Moisture content wet-basis $\left(\mathrm{MC}_{\mathrm{wb}}\right)$ was determined at the beginning and at the end of each trial with the gravimetric method (CEN/TS 14774-2, 2009), on random samples obtained by cutting segments ('biscuits') from the logs (destructive sampling). Overall, 30 samples were collected at the beginning of the trials prior to loading the logs onto the pallets. Since the logs came all from the same initial source stock, variability was assumed to be limited. However, diameter was recorded for each 'biscuit' to check for correlation with moisture content. In contrast, 120 samples were collected at the end of the trials (6 per stack) in order to account for the potentially higher variability resulting from treatment differences. The six samples per stack were collected at two height locations (medium and high) and three different distances from the

Table 1 Summary of the experimental design

\begin{tabular}{lcccc}
\hline Season & Size & Cover & Split & Replicates \\
\hline Summer & Small & No & - & 3 \\
& Small & Yes & - & 3 \\
& Large & Yes & Yes & 3 \\
Winter & Large & Yes & No & 3 \\
& Small & No & - & 2 \\
& Small & Yes & - & 2 \\
& Large & No & No & 1 \\
& Large & Yes & No & 1 \\
& Large & No & Yes & 1
\end{tabular}

Note: Splitting does not apply to small logs. end of the $\log (30 \mathrm{~cm}, 60 \mathrm{~cm}$ and $90 \mathrm{~cm})$. This provided for a more appropriate average.

The variation of moisture content during the duration of the trials was determined by weighing each stack at 1 to 4 week intervals (non-destructive sampling). Stacks were weighed by temporarily placing portable stock scales under the pallets. Each pallet was lifted on one side with a trolley jack in order to place the scale under it. Then the pallet was lowered on the scale plate to obtain a reading. Weight data were used to calculate moisture content, on the assumption that any decrease in pallet weight was directly related to moisture content loss. Weight data were re-calibrated once each trial was complete using the gravimetric moisture content values obtained following destructive sampling at the end of the trials.

Climate data were obtained from the meteorological stations of the National Institute for Water and Atmospheric Research (NIWA 2010). These were located $1.2 \mathrm{~km}$ from the summer trial site (Mosgiel) and $12.5 \mathrm{~km}$ from the winter trial site $(\mathrm{Okuku})$. Climatic conditions were averaged over the number of days between each weighing in order to obtain a representation of the climatic conditions between two subsequent weight points. Recorded climate data included: air temperature, wind speed, air humidity, rainfall and evaporation.

Analyses of variance (ANOVA) was carried out on sample moisture content data between treatments at the end of the experiment. Indicator variables were designed to represent different treatments (Olsen et al. 1998). Regression analysis was used using the time-series moisture content data obtained from weighing to test the relationship between moisture content and storage time (SAS 1999). Higher order time, as well as interaction-factors, was considered in the regression to account for the non-linear drying rate, relative to the treatments.

\section{Results}

Moisture content wet basis $\left(\mathrm{MC}_{\mathrm{wb}}\right)$ of the pre-trial samples collected from the logs and ranged from 45 to $60 \%$ for the summer trial, and 53 to $67 \%$ for the winter trial. The average air temperature, average wind speed, average humidity, average rainfall and average daily evaporation are presented in Table 2.

The average $\mathrm{MC}_{\mathrm{wb}}$ of the logs in the summer trial (Mosgiel) was 53.2\% (standard deviation 4.8), and 57.7\% (standard deviation 3.4) for the winter trial (Okuku). There was no relationship between $\mathrm{MC}_{\mathrm{wb}}$ and log diameter $\left(R^{2}=0.11, p=0.79\right.$ and $R^{2}=0.09, p=0.87$ respectively), so all Mosgiel log stacks were considered to have an initial $\mathrm{MC}_{\mathrm{wb}}$ of $53.2 \%$ and the Okuku trial $57.7 \%$. During the Mosgiel trial, the weather was warm and dry with a few minor rain events. The total rainfall over the 24 weeks of storage was $234 \mathrm{~mm}$. In Okuku, the weather 
Table 2 Initial range of log moisture content and weather data for duration of study

\begin{tabular}{lcc}
\hline & $\begin{array}{l}\text { Summer } \\
\text { (Mosgiel) }\end{array}$ & $\begin{array}{c}\text { Winter } \\
\text { (Okuku) }\end{array}$ \\
\hline $\begin{array}{l}\text { Log moisture content range } \\
\text { (\% wet basis) }\end{array}$ & $45-60$ & $53-67$ \\
Average air temperature $\left({ }^{\circ} \mathrm{C}\right)$ & 13 & 7 \\
Average relative humidity $(\%)$ & 76 & 85 \\
Average rainfall (mm/week) & 9.75 & 20.0 \\
$\begin{array}{l}\text { Average total daily evaportation } \\
\text { (mm/day) }\end{array}$ & 3.2 & 1.4 \\
Average daily windspeed $(\mathrm{m} / \mathrm{s})$ & 3.7 & 2.8 \\
\hline
\end{tabular}

was cold and wet; total rainfall over the 17 weeks of storage was $340 \mathrm{~mm}$ with $115 \mathrm{~mm}$ of this falling in the first week alone.

The greatest decrease in $\mathrm{MC}_{\mathrm{wb}}$ (20-32\% depending on treatment) occurred under summer storage (Table 3). The decrease was greatest for uncovered small logs, and smallest for covered large logs. Covered small logs and covered represented an intermediate class with no significant internal differences in terms of final $\mathrm{MC}_{\mathrm{wb}}$. Large logs lost less water than small logs, but splitting restored the balance, as no difference was found in the $\mathrm{MC}_{\mathrm{wb}}$ of small logs and large split logs. As expected, $\mathrm{MC}_{\mathrm{wb}}$ after winter storage did not decrease as much as during summer storage, due to the less favourable weather conditions. After 17 weeks, the average decrease of $\mathrm{MC}_{\mathrm{wb}}$ was 7 percent.

At the end of the summer storage period, log ends were drier than the rest (Table 4). The same effect was not observed during the winter trial (Table 4). At the end of the trials, the $M_{\mathrm{wb}}$ estimates obtained with the gravimetric method were compared with those $\left(\mathrm{MC}_{\text {diff }}\right)$ obtained by weighing the stacks and relating weight loss to the initial
$\mathrm{MC}_{\mathrm{wb}}$. The results are also shown in Table 3, where gravimetric estimates $\left(\mathrm{MC}_{\mathrm{wb}}\right)$ were assumed as the actual reference values, whereas stack-weight estimates $\left(\mathrm{MC}_{\mathrm{diff}}\right)$ were considered as the predicted figures needing validation. Differences between the two analytical methods were observed, ranging between -1 and $+7 \%$, with a mean absolute error of $3.7 \%$.

Given that decrease in stack weight was a good proxy for moisture content, it was possible to track the rate of drying over time. For the summer trial, drying was most rapid during the first 10 weeks, when $\mathrm{MC}_{\text {diff }}$ decreased by 15 to $30 \%$, depending on treatment. Drying continued until the end of the experiment (24 weeks), but at diminishing rates (Figure 1). There was also a clear differentiation between treatments, with large logs and covered small logs drying less and less rapidly than uncovered small logs and large split logs. For the summer trial $(n=144)$, the following regression model was developed to predict $\mathrm{MC}_{\text {diff }}$ as a function of drying time:

$$
\begin{aligned}
& \mathrm{MC}_{\text {diff }}= 55.1-3.57 \mathrm{Week}+0.80 \mathrm{Week}^{2} \\
&+0.358 \mathrm{Week} * \mathrm{SMLCOV}+0.919 \text { Week } \\
& * \text { LRGCOV } \\
&\left(R^{2}=0.944 ; p<0.0001\right)
\end{aligned}
$$

Where:

Week = number of weeks in storage;

$\mathrm{SMLCOV}=0$, or 1 if the small $\operatorname{logs}(<35 \mathrm{~cm}$ diameter $)$ are covered;

LRGCOV $=0$, or 1 if the stack is made of large logs ( $\geq 35 \mathrm{~cm}$ diameter) and covered

All parameters in this regression model were significant at $p<0.05$ and it was able to explain most of the variation in the data set. As a second order quadratic

\begin{tabular}{|c|c|c|c|c|c|c|c|}
\hline Season & Size & Treatment & Actual $\mathrm{MC}_{\mathrm{wb}}{ }^{1,2}$ & SD & Predicted $M C_{\text {diff }} 1,2$ & SD & Difference \\
\hline \multirow[t]{4}{*}{ Summer } & Small & Uncovered & $21.3 \mathrm{a}$ & 1.5 & 18.0 & 2.9 & 3.3 \\
\hline & Small & Covered & $24.8 b$ & 2.2 & 23.0 & 1.2 & 1.8 \\
\hline & Large & Covered & $33.5 c$ & 3.4 & 32.0 & 1.5 & 1.5 \\
\hline & Large & Covered \& Split & $27.0 \mathrm{~b}$ & 3.7 & 20.0 & 0.5 & 7.0 \\
\hline \multirow[t]{6}{*}{ Winter } & Small & Uncovered & $44.9 \mathrm{~d}$ & 7.3 & 47.5 & 1.5 & -2.6 \\
\hline & Small & Covered & $45.8 d$ & 7.5 & 51.9 & 10.5 & -6.1 \\
\hline & Large & Covered & $45.8 d$ & 5.0 & 51.9 & - & -6.1 \\
\hline & Large & Covered \& Split & $44.9 \mathrm{~d}$ & 8.8 & 45.9 & - & -1.0 \\
\hline & Large & Uncovered & $50.3 d$ & 7.4 & 55.8 & - & -5.5 \\
\hline & Large & Uncovered \& Split & $50.9 d$ & 8.5 & 48.4 & - & 2.5 \\
\hline
\end{tabular}
function, with interactions, was chosen for the summer

Table 3 Comparison of moisture content wet-basis obtained through destructive gravimetric sampling (Actual, $\mathrm{MC}_{\mathrm{wb}}$ ) and stack weighing (Predicted, $M_{\text {diff }}$ )

${ }^{1}$ At 24 weeks for the summer trial and 17 weeks for the winter trial.

${ }^{2}$ Average initial moisture content was $53.2 \%$ for the summer trial and $57.7 \%$ for the winter trial (all treatments).

Note: different letters on the average values in the same column indicate differences with statistical significance at the $5 \%$ level. 
Table 4 Wood moisture content at the end of the trials at different distances from the log end

\begin{tabular}{|c|c|c|c|c|c|c|}
\hline \multirow{2}{*}{$\begin{array}{c}\text { Length } \\
\text { cm }\end{array}$} & \multicolumn{3}{|c|}{ Summer } & \multicolumn{3}{|c|}{ Winter } \\
\hline & $\mathrm{MC}_{\mathrm{wb}}{ }^{1,2}$ & SD & & $\mathrm{MC}_{\mathrm{wb}}{ }^{1,2}$ & SD & \\
\hline 30 & 24.1 & 5.0 & A & 48.0 & 6.3 & C \\
\hline 60 & 27.8 & 6.7 & B & 44.2 & 8.6 & C \\
\hline 90 & 28.0 & 7.5 & B & 47.8 & 7.1 & C \\
\hline
\end{tabular}

${ }^{1}$ At 24 weeks for the summer trial and 17 weeks for the winter trial.

${ }^{2}$ Initial moisture content was $53.2 \%$ for the summer trial and $57.7 \%$ for the winter trial (all treatments).

log drying model it is important that predictions using this regression should not be extrapolated beyond the 24 week duration of the study.

In contrast, in the winter trial no treatment was significantly different based on actual $\mathrm{MC}_{\mathrm{wb}}$ (Table 3). The average $\mathrm{MC}_{\mathrm{wb}}$ for all treatments at week 17 was $47.1 \%$, a decline of $10.6 \%$ from the initial moisture content of $57.7 \%$. Figure 2 shows $\mathrm{MC}_{\text {diff, }}$ as predicted by change in loaded stack weight over the 17 week storage period. Cool weather, high humidity and regular rainfall events resulted in no drying taking place in the first five weeks. A large rainfall event in week seven increased the $M C_{\text {diff }}$ of the uncovered large log treatments. Overall $M_{\text {diff }}$ decreased at a rate of $0.4 \%$ per week $(n=102, F=48.4)$, with only $38 \%$ of the variation explained by this singlevariable model $\left(R^{2}=0.38\right)$.

\section{Discussion}

Natural drying is based on the air-moisture gradient, which is much lower in winter than in summer (Ciganas and Railas 2010). That explains the limited moisture content reduction reported in this study for winter storage. As winter conditions did not allow any significant drying, treatment effect remained undemonstrated. Hence, we need to rely on the summer trial to examine and discuss the effect of the different treatments. Fortunately, the New Zealand summer seems to offer favourable conditions for moisture loss, which in the best case dropped from an average of $53 \%$ to $21 \%$ in just 24 weeks, and in the worst case to $33 \%$. In comparison under an Irish summer, such a reduction is only obtained after at least 35 weeks (Kent 2010), and other European studies indicate an average $\mathrm{MC}_{\mathrm{wb}}$ of around $40 \%$ after summer storage of un-debarked biomass logs (Spinelli 2005). The faster summer drying obtained in the New Zealand trial could be related to more favourable climate or site conditions, as well as to the relative small size of the stacks and the extensive debarking of test logs, all of which are known to accelerate drying (Röser et al. 2010).

In turn, the faster drying of debarked logs may illustrate the significance of radial water movements. While absorbed free water flows primarily along the stem and is expelled mainly from the log ends (Walker 2006), there must be a secondary movement across the stem if small diameter logs and large split logs dry better than large whole logs, as also reported by Abbot et al. (1997). Compared to large diameter whole logs, both small diameter logs and split logs offer a larger surface area to mass ratio and a smaller distance between the log centre and its surface, which water must reach in order to evaporate. Splitting may also accrue a possible benefit from exposing core wood and shortening the average path length that water has to move. For the same reasons, splitting may prove to be especially beneficial with long logs as the relative proportion of radial versus longitudinal drying increases. However, it is still uncertain whether the cost of splitting is offset by the benefit obtained through it. This is difficult to determine, because the cost of splitting may vary according to equipment

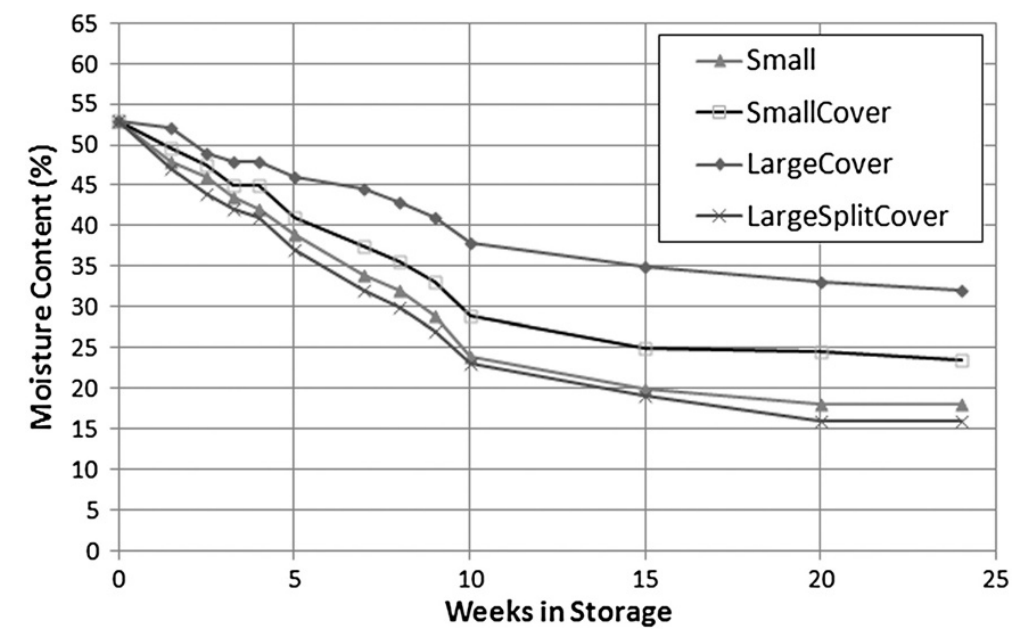

Figure 1 Estimated wood moisture content ( $M C_{\text {diff }}$ based on changes in pallet weight) during the summer biomass drying trial (Mosgiel). 


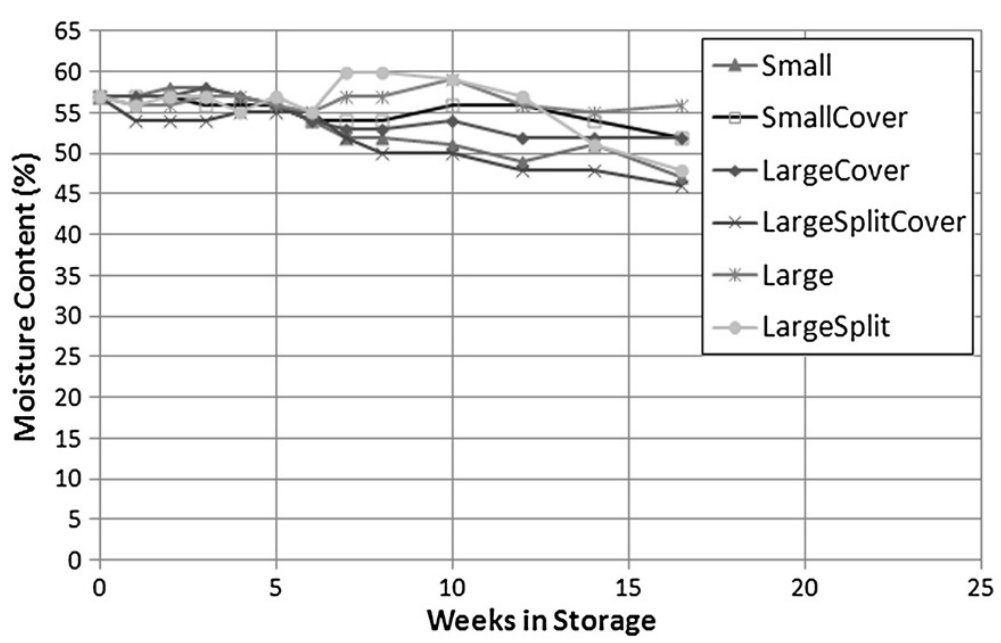

Figure 2 Estimated wood moisture content ( $M C_{\text {diff }}$ based on changes in pallet weight) during the winter biomass drying trial (Okuku).

and technique, and the benefits should include the higher heating value of the end product, as well as the different performance of the chipper when negotiating split or whole logs. A tentative calculation conducted for the actual trial would indicate a splitting cost of NZ\$15 per tonne and a value increase at the end of storage equal to

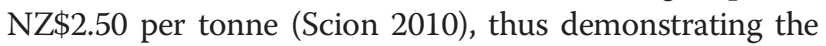
poor financial viability of log splitting. However, this calculation is based on a rather inefficient splitting technique, and does not account for the potentially superior performance obtained when chipping even-sized split material.

Many studies indicate that un-comminuted wood biomass keeps drier if stored under cover. Most Nordic reports agree on similar values for the lower $\mathrm{MC}_{\mathrm{wb}}$ achieved when covering, with respect to uncovered control treatments: 4 to $7 \%$ (Lethikangas and Jirjis 1993); 6\% (Nurmi and Hillebrand 2007); 7\% (Nurmi 2001); 10\% (Jirjis 1995). In contrast, our study found that covered small logs dried significantly less than uncovered small logs during summer storage, whereas covered and uncovered treatments showed no significant differences during winter storage. In Nordic countries, biomass tends to have a lot of small diameter branches and small diameter stem wood and is, therefore, prone to rewetting due the high surface area to mass ratio, and this may help explain the difference.

The reasons for the lack of treatment differences during winter storage have already been discussed. Concerning summer storage, it may be important to stress that test stacks were prepared immediately after harvesting, leaving logs on the cutover for a very short time. Under Nordic practice, forest residue is left on the cutover several weeks, before being forwarded to a landing, stacked and eventually covered. Hence, residue is left uncovered in small piles for initial fast transpirational drying (Gislerud 1990), and covered only after moisture content has been considerably reduced. Once the wood is stacked, air circulation is restricted and drying slows down (Nurmi 1999). Under these conditions, covering does not specifically favour drying, but it prevents the re-wetting of dry material (Filbakk et al. 2011). In contrast, covering fresh material may be detrimental, because the protection against the limited summer rainfall is far outweighed by the reduced airflow through the stack and the lower surface temperature of the wood. The poor performance of stack covers in our study is likely related to technique, rather than to covering itself. Covering is probably unjustified for summer storage, and this is consistent with the binwood residue study carried out by the Clean Energy Centre (2009), but it may still play a significant role if logs were stored for a longer period and through the rainy season.

A better strategy would consist in leaving the stacks uncovered for the first 10 to 12 weeks, in order to maximize the rapid initial drying illustrated in Figure 1. Then the stacks could be covered to prevent re-wetting, especially if storage would extend into a rainy winter season.

The profile of moisture loss presented in Figure 1 is typical of summer drying, and similar in shape to those reported in many other studies, such as the drying trial of exposed stem wood and branches completed by Hall (2000). Drying rate is very high at the beginning, and it decreases with time, as free water is removed from the $\log$. Once $\mathrm{MC}_{\mathrm{wb}}$ reaches $20-25 \%$, the fibre saturation point is reached and any further loss implies the removal of bound water. This is bound within the cell walls and it is much harder to extract compared to free absorbed water, flowing through the vascular structures. In the presence of precipitation, moisture can increase again, according to a typical seasonal pattern (Afzal et al. 2010). This trend is well reflected by a quadratic equa-tion, also used for the same purpose by other authors (Laurila and Lauhanen 2010). 
The moisture content of logs was found to be evenly distributed throughout the stacks in the current study. This result may be due to the small size of the stacks used here. In contrast, gradients in moisture content of logs in relation to stack position have been documented in other studies that were conducted on much larger piles (Kent 2010).

\section{Conclusions}

The moisture content of radiata pine logs for biomass use can be significantly reduced with summer storage. After 24 weeks, the initial moisture content above 50\% (wet base) can drop to between 33 and 21\%, making biomass logs an excellent fuel. The best summer storage technique is the simplest, and consists of stacking small logs without any cover. Large logs could be split in order to accelerate drying. Due to wet and cold weather conditions, winter storage does not offer the same benefits, with the logs drying very little over 17 weeks. Covering does not help. In fact, covering is designed to prevent rewetting of dry logs, and not to favour drying of wet logs. On the contrary, summer-dried logs could be covered if storage was to continue over the winter season.

\section{Competing interests}

The authors declare that they have no competing interests.

\section{Authors' contribution}

The concept for the study, the proposal for funding, the final data analyses and manuscript review process was primarily undertaken by RV. The study setup and data collection was undertaken by HB within the scope of his final year honours project, with Visser as his supervisor. The initial manuscript draft based on the honours report, including a more comprehensive literature review, was undertaken by RS. All authors read and approve the final manuscript.

\section{Acknowledgements}

The authors gratefully acknowledge the technical and financial support of the New Zealand Energy Efficiency and Conservation Authority (EECA). We also thank City Forests (summer Mosgiel trial) and Rayonier (winter Okuku trial) for providing the logs and sites for the study.

\section{Author details}

${ }^{1}$ Director of Studies Forest Engineering - Canterbury University, Private Bag, 4800 Christchurch, New Zealand. ${ }^{2}$ Forest Engineering - Canterbury University, Private Bag, 4800 Christchurch, New Zealand. ${ }^{3}$ CNR IVALSA, Via Madonna del Piano 10 Sesto, Fiorentino, (FI), Italy.

Received: 11 December 2013 Accepted: 12 December 2013

Published: 17 January 2014

\section{References}

Abbot, P, Lowore, J, Khofi, C, \& Werren, M. (1997). Defining firewood quality: a comparison of quantitative and rapid appraisal techniques to evaluate firewood species from a Southern African savanna. Biomass \& Bioenergy, 12, 429-437.

Afzal, M, Bedane, A, Sokhasanj, S, \& Mahmood, W. (2010). Storage of comminuted and uncomminuted forest biomass and its effect on fuel quality. BioResources, 5(1), 55-69.

Baker, S, Westbrook, M, \& Greene, D. (2010). Evaluation of integrated harvesting systems in pine stands of the southern United States. Biomass \& Bioenergy, $34,720-727$.
Brammer, JG, \& Bridgewater, AV. (1999). Drying technologies for an integrated gasification bio-energy plant. Renewable and Sustainable Energy Reviews, 3, 243-289.

CEN/TS 14774-2:2009. (2009). Solid biofuels - methods for determination of moisture content. Total moisture: simplified method: Oven dry method.

Chau, J, Sowlati, T, Sokhansanj, S, Preto, F, Melin, S, \& Bi, X. (2009). Economic sensitivity of wood biomass utilization for greenhouse heating application. Applied Energy, 86(5), 616-621.

Ciganas, N, \& Raila, A. (2010). Analysis of heating value variations in stored wood. Proceedings of the Conference "Engineering for rural development", Jelgava 27-28 May 2010

Clean Energy Center. (2009). Greater Wellington Regional Council Forest Residue Utilisation Trial. Taupo, New Zealand: Published by Clean Energy Centre.

Energy Efficiency and Conservation Authority. (2010). Good Practice Guide: production of wood fuel form forest landings. Technical Guide 9.0.

Filbakk, T, Høibø, O, \& Nurmi, J. (2011). Modelling natural drying efficiency in covered and uncovered piles of whole broadleaf trees for energy use. Biomass and Bioenergy, 35, 454-463.

Gislerud, O. (1990). Drying and storing of comminuted wood fuels. Biomass, $22,229-244$

Hall, P. (2000). Effects of storage on fuel parameters of piles and comminuted logging residues. LIRO Report Vol. 25, No. 5. Rotorua, New Zealand: Logging Industry Research Organisation.

Hall, P, \& Jack, M. (2009). Bioenergy options for New Zealand: Analyses of large scale bioenergy from Forestry (Productivity, Land use and Environmental \& Economic Implications). Rotorua, New Zealand: Scion.

Hart, C. (1982). SIMSOR: A computer simulation of water soprtion in wood. Wood Fiber, 32, 26-31.

Hillring, B. (1997). Price trends in the Swedish wood-fuel market. Biomass \& Bioenergy, 12, 41-51.

Holmberg, H, \& Ahtila, P. (2004). Comparison of drying costs in biofuel drying between multi-stage and single stage drying. Biomass \& Bioenergy, 26, 515-530.

Jirjis, R. (1995). Storage and drying of wood fuels. Biomass \& Bioenergy, 9, 181-190.

Johansson, A, Fyhr, C, \& Rasmuson, A. (1997). High temperature convective drying of wood chips with air and superheated steam. International Journal of Heat and Mass Transfer, 40, 2843-2858.

Junginger, M, De Visser, E, Hjort-Gregersen, K, Koornneef, J, Raven, R, Faaij, A, \& Turkenburg, W. (2006). Technological learning in bioenergy systems. Energy Policy, 34, 4024-4041

Kent, T, Coates, E, \& Kofman, P. (2010). Moisture Content Variation in Forest Biomass During Storage. Proceedings of the COST FP902 Conference, Trento, Italy, 8 October 2010

Laurila, J, \& Lauhanen, R. (2010). Moisture content of Norway spruce stump wood at clear cutting areas and roadside storage sites. Silva Fennica, 44, 427-434.

Lethikangas, J, \& Jirjis, R. (1993). Valtlagring av averkningsrester fran barrtrad under varierande omsta ndigheter (Storing of logging residues under various conditions). Uppsala, Sweden: Sveriges Lantbruksuniversitet, Institutionen for virkeslara, Rapport nr. 235

Mcllveen-Wright, DR, Williams, BC, \& McMullan, JT. (2001). A re-appraisal of wood-fired combustion. Bioresources Technology, 76, 183-190.

National Institute of Water and Atmospheric Science (NIWA). (2010). The National Climate Database - Database Query Form. http://cliflo.niwa.co.nz/ retrieved September 2010

Nurmi, J. (1999). The storage of logging residue for fuel. Biomass \& Bioenergy, $17,41-47$.

Nurmi, J. (2001). Storage alternatives affect fuelwood properties of Norway spruce logging residues. New Zealand Journal of Forestry Science, 37(3), 289-97.

Nurmi, J, \& Hillebrand, K. (2007). The characteristics of whole-tree fuel stocks from silvicultural cleanings and thinnings. Biomass \& Bioenergy, 31, 381-392.

Olsen, E, Hossain, M, \& Miller, M. (1998). Statistical comparison of methods used in harvesting work studies. Corvallis, OR, USA: Oregon State University Forest Research Laboratory: Research Contribution no. 23.

Pennial, C. (2008). Feasibility Study into the Potential for Gasification Plant in the New Zealand Wood Processing Industry. Christchurch, New Zealand A thesis submitted in partial fulfilment of the requirements for the Degree of Master of Engineering in Chemical and Process Engineering. University of Canterbury.

Petterson, M, \& Nordfjell, T. (2007). Fuel quality changes during seasonal storage of compacted logging residues and young trees. Biomass \& Bioenergy, 31, 789-792. 
Raghavan, G, Rennie, T, Sunjka, P, Orsat, V, Phaphuangwittayakul, W, \& Terdtoon, P. (2005). Overview of new techniques for drying biological materials with emphasis on energy aspects. Brasilian Journal of Chemical Engineering, 22, 195-201.

Reuss, M, Benkert, S, Aeberhard, A, Martina, P, Rausch, G, Rentzell, B, \& Sogari, N. (1997). Modelling and experimental investigation of a pilot plant for solar wood drying. Solar Energy, 59(259), 270.

Röser, D, Erkkilä, A, Mola-Yudego, B, Sikanen, L, Prinz, R, Heikkinen, A, Kaipainen, H, Oravainen, H, Hillebrand, K, Emer, B, \& Väätäinen, K. (2010). Correct text and formatting is: Natural drying methods to promote fuel quality enhancement of small energywood stems. Working Papers of the Finnish Forest Research Institute, 186. Joensuu, Finland: Finnish Forest Research Institute.

Rupar, K, \& Sanati, M. (2003). The release of organic compounds during biomass drying upon the feedstock and/or altering drying heating medium. Biomass \& Bioenergy, 25, 615-622.

SAS Institute Inc. (1999). StatView Reference (pp. 84-93). Cary, NC, USA: SAS Publishing.

Scion. (2011). Woody biomass for boiler fuel - Guidelines for Payment by Energy Content. Rotorua, New Zealand: Scion. Downloaded on 12 May 2011 from: http://www.bkc.co.nz.

Simpson, W, \& Hart, C. (2001). Method for estimating air-drying times of lumber. Forest Products Journal, 51, 56-63.

Simpson, W, \& Wang, X. (2003). Estimating air drying times of small-diameter ponderosa pine and Douglas-fir logs. Research Paper FPL-613. Madison, WI, USA: U.S. Dept. of Agriculture, Forest Service, Forest Products Laboratory.

Spets, J, \& Ahtila, P. (2002). Improving the power-to-heat ratio in CHP plants by means of a biofuel multistage drying system. Applied Thermal Engineering, $22,1175-1180$

Spinelli, R. (2005). Forest chips. In R Spinelli (Ed.), Guidelines for the development of a forest chips supply chain model (pp. 93-97). Belluno, Italy: GAL Prealpi e Dolomiti.

Spinelli, R, Ivorra, L, Magagnotti, N, \& Picchi, G. (2010). Performance of a mobile mechanical screen to improve the commercial quality of wood chips for energy. Biores. Technol., 102(15), 7366-7370.

Strelher, A. (2000). Technologies of wood combustion. Ecological Engineering, $16,25-40$.

Stupak, A, Asikainen, A, Jonsel, M, Karltun, E, \& Lunnan, A. (2007). Sustainable utilisation of forest biomass for energy-Possibilities and problems: Policy, legislation, certification, and recommendations and guidelines in the Nordic, Baltic, and other European countries. Biomass \& Bioenergy, 31, 666-684.

Suadicani, K, \& Heding, N. (1992). Wood preparation, storage, and drying. Biomass Bioen., 2, 49-156.

Svoboda, K, Martinec, J, Pohořely, M, \& Baxter, D. (2009). Integration of biomass drying with combustion/gasification technologies and minimization of emissions of organic compounds. Chemical Papers, 63, 15-25.

Visser, R, Spinelli, R, \& Stampfer, K. (2009). Integrating biomass recovery operations into commercial timber harvesting: the New Zealand situation. In 2009 Council of Forest Engineering (COFE) Conference Proceedings: "Environmentally Sound Forest Operations." Lake Tahoe, June 15-18, 2009.

Walker, J. (2006). Primary wood processing (2nd ed.). Dordrecht, Netherlands: Springer Verlag

Yoshida, T, Sasaki, H, Takano, T, \& Sawabe, O. (2010). Dewatering of high-moisture wood chips by roller compression method. Biomass \& Bioenergy, 34, 1053-1058.

doi:10.1186/1179-5395-44-3

Cite this article as: Visser et al:: Determining the effect of storage conditions on the natural drying of radiata pine logs for energy use. New Zealand Journal of Forestry Science 2014 44:3.

\section{Submit your manuscript to a SpringerOpen ${ }^{\circ}$ journal and benefit from:}

- Convenient online submission

- Rigorous peer review

- Immediate publication on acceptance

- Open access: articles freely available online

- High visibility within the field

- Retaining the copyright to your article

Submit your next manuscript at $>$ springeropen.com 